\title{
DOCTORS
}

Don't be afraid to ask your doctor questions - they can set you on the right track for many things, says Laura Swaffield.

\section{USEFUL INFORMATION}

\section{British Medical \\ Association \\ BMA House}

Tavistock Square London WC1H 9.JP

Tel: 01713874499

General Medical Council 44 Hallam Street London W1N 6AE Tel: 01715807642
G eneral practitioners will be able to diagnose and treat many problems themselves. When they cannot, they should make a referral to a hospital specialist.

They work closely, as a team, with community nurses and health visitors. Increasingly, these teams are expanding to include other workers such as counsellors and physiotherapists.

Many GPs now also run health education sessions on topics such as stress, smoking, slimming, high blood pressure or heart health. Quite a few GPs will now refer you (on the NHS) to complementary therapists, such as osteopaths, homoeopaths or acupuncturists.

GPs are also useful sources of information on other services available locally, including social services and voluntary groups. It is always worth asking.

A sympathetic GP, who knows you and the person you care for as individuals, can make all the difference. And their opinion can be crucial in getting what you need, from better housing to social security benefits. If you are not happy with your GP, you can change (see 'The NHS: Your rights', page 9).

\section{HOSPITAL DOCTORS}

Hospital doctors are specialists. The most senior among them are the consultants, who are responsible for all the patients within their specialist area. In practice, they delegate much of the work (under their supervision) to juniors - all qualified doctors.

The lowest grade is house officer, followed by senior house officer, registrar and senior registrar. These junior doctors will be doing postgraduate studies as they work their way towards consultant status. Often, a registrar will be very well qualified and experienced.

There are dozens of different specialisms. Traditionally, however, doctors have concentrated on curing people. There is less interest in chronic (long-term) conditions. This is now changing, but slowly. There are now quite a few geriatricians, for instance. Much more rare are specialists in other useful areas like pain control, psychogeriatrics, rehabilitation, physical disability and rheumatology. If any of these might be useful, ask your GP. You may be lucky.

\section{DON'T BE INTIMIDATED!}

In the past, doctors were trained to be rather remote and godlike. This, too, is changing, although some doctors find it easier than others! Don't be afraid to ask questions, express your worries, or admit that you don't understand. It helps if you list your questions in advance, and write down what the doctor says for future reference.

Do remember that, in the end, doctors are not the be-all and end-all. Many of the other professionals described here are more geared up to dealing with the problems of the person you care for, which are often problems of coping, not curing. A good GP can, however, set you on the right track. 